This is an Accepted Manuscript of an article published by Taylor \& Francis in Educational Review on 05/06/17, available online:

http://www.tandfonline.com/doi/full/10.1080/00131911.2017.1330252. 


\title{
Provision for Mathematically Able Children in Primary Schools: A Review of Practice Five Years After England Dropped the Gifted and Talented Initiative
}

\author{
Christos Dimitriadis \\ Kingston University London, UK \\ C.Dimitriadis@kingston.ac.uk \\ Jan Georgeson \\ Plymouth University, UK \\ janet.georgeson@plymouth.ac.uk
}

7 March 2017

Author Note

Christos Dimitriadis, Faculty of Health, Social Care and Education, School of Education, Kingston University London; Jan Georgeson, Faculty of Arts \& Humanities, Plymouth Institute of Education, Plymouth University.

Correspondence concerning this article should be addressed to Dr Christos Dimitriadis, Room KHEBLG08, School of Education, Faculty of Health, Social Care and Education, Kingston Hill campus, Kingston Hill, KT2 7LB. E-mail: C.Dimitriadis@kingston.ac.uk 


\title{
Provision for Mathematically Able Children in Primary Schools: A Review of Practice Five Years After England Dropped the Gifted and Talented Initiative
}

\begin{abstract}
After the abandonment of the Gifted and Talented initiative and the recent developments in mathematics educational policy (i.e. the new national curriculum and the "mastery" initiative), this research project aimed to explore the current primary school situation regarding educating the "most able" children in mathematics, along with teachers' views, experiences and perceived needs. This was a pilot research study gathering insights from a small number of schools in order to identify areas that could be improved by larger-scale research studies. The findings obtained from 49 schools under four local educational authorities in southwest England suggested that the education of children with the ability or potential to excel in mathematics has reached a crucial stage. There is a real need for specialised support and guidance in recognising and developing mathematical potential for classroom teachers and school leaders who try on their own to discover what could enable them to meet the government's educational target of achieving "excellence everywhere". This support should have underpinnings from theory and research, preventing our schools from using questionable practices or repeating methods that have failed in the past. This article highlights research areas specifically for this reason. It also raises some questions with potential implications for the Special Educational Needs Coordinator's role, as well as for implementing new initiatives like the mathematics "mastery curriculum".
\end{abstract}

Keywords: able children; gifted education; mathematics education; primary / elementary years; education policy; mastery

\section{Introduction}

Despite the interest over the last three decades in the education of children who can or have the potential to perform at a higher level in mathematics and other academic subjects, the albeit limited research on this topic consistently shows gaps between theory and practice, highlighting this as a problematic area for education in England (Casey and Koshy 2013; 
Dimitriadis 2016; Office for Standards in Education [Ofsted] 2009; Smithers et al. 2012;) and elsewhere (Cox, Daniel, and Boston 1985; Boyes 2004; Freeman, Raffan, and Warwick 2010; Westberg et al. 1993; Westberg and Daoust 2004). However, following recent changes in England, the dimensions of this problem could change. After the abandonment of the Gifted and Talented (G\&T) policy in 2010, along with the introduction of the new National Curriculum in September 2014 (Department for Education 2014), the question could extend beyond the theory-practice gap to include the existence - or rather the lack — of any provision for students capable of excelling at higher levels in an academic domain such as mathematics.

For a decade from1999 to2010, the education of gifted children had been a priority for educational planning in both England and Wales, as they shared a common educational policy until 2010. This was supported by a G\&T policy (Department for Children, Schools, and Families 2008a, 2008b), as well as a designated team (National Strategies) responsible for developing supporting materials and short training courses for practitioners, which were offered through the local education authorities (LEAs). Research conducted during that period (Dimitriadis 2012; Koshy and Pinheiro-Torres 2013; Koshy, Pinheiro-Torres, and Portman-Smith 2012; Ofsted 2009; Williams 2008) revealed that, despite the high interest and schools' attempts to respond pragmatically to the government's G\&T initiative, there were problems with its application to classroom practice. The studies recommended improved and more systematic training for teachers. Dimitriadis's (2012) study in particular found provision offered to pupils identified as more able or gifted to be rather random and not necessarily matching their needs, even in special classes (e.g. pull-out groups) that aimed to offer challenging and enriching opportunities. This result indicated that the question was not whether schools were doing something for their most able children beyond or different from the usual instruction, but rather whether that something was appropriate and targeted the right pupils.

Towards the end of 2010, the government decided to drop the programme and to disband the team responsible for overseeing it, taking into consideration the G\&T programme's review by a government-selected committee (House of Commons 2010), as well as the programme's growing criticism (e.g. Evans 2010). The terms "gifted", "talented", and their derivatives are no longer used so as to avoid any association with the abandoned and unsuccessful G\&T initiative. They have since been replaced by the terms "highly able" (Smithers et al. 2012), "more able", and "most able" (Ofsted 2015a, 2015b). A new national curriculum 
(Department for Education 2014) and strategic plan (White Paper: "Excellence Everywhere" [Department for Education 2016]) have reshaped the educational context in England. Both recognise the need to promote academic potential in schools. The White Paper (Department for Education 2016, 98) sets high expectations across the educational system, stating that the most academically able students can boost the "country's economic development and growth". "[S]chools that stretch their brightest pupils" will be rewarded through "the new focus on progress measures in performance tables", as well as new examinations at the end of primary school for the General Certificate of Secondary Education (GCSE). The new national curriculum recommends mathematics-enriched and challenging work in the primary school for those who "grasp concepts rapidly" (108). The Ofsted (2015b) urged its inspectors to "pay particular attention to whether more able pupils in general and the most able pupils in particular are achieving as well as they should" (63). However, neither the government's strategic plan and national curriculum nor Ofsted's publications set any particular standard, nor do they provide any guidance for how academic potential might be recognised and fulfilled. This is the entire responsibility of the school management and leadership team, who should find out for themselves what works best by drawing on empirical evidence (Department for Education 2016). In addition to this, the Department of Education decided to support the "mastery" initiative, which is based on the Shanghai model of mathematics. A mastery curriculum calls for all children to learn the same mathematics content, with more support provided for those who struggle and more demanding problems provided for those who can do more; this however is achieved through adding depth to the same content rather than through material differentiation or acceleration (National Centre for Excellence in the Teaching of Mathematics 2014).

Considering these new developments, along with the fact that highly able children's needs were not fully addressed even when G\&T policy and support were in place and interest was high, the following research questions were set for investigation: Are primary schools interested in educating children with the potential to excel in mathematics? Do the schools take any educational measures for such students and, if so, what are they? And what are practicing teachers' and school leaders' perceptions, experiences and perceived needs regarding educating highly able mathematics students? This study aimed to answer these questions through a questionnaire sent to primary schools within four southwest England LEAs. The theoretical framework that guided the development of the study and the analysis of the data is presented in the following section. 


\section{Theoretical Perspectives}

The idea that there are individuals who have a special mathematical ability which allows them to excel in technology and innovation, where mathematics prowess is needed, is not new. Krutetskii (1976) called this special ability a "mathematical cast of mind", suggesting that individuals who have it can recognise mathematical relationships, bonds, and practical dependencies in situations in which other people cannot. Many years later, Gardner's (1983; 1999) theory of "multiple intelligences" distinguished a logical-mathematical intelligence, amongst a number (seven or eight) of distinct "intelligences". Each intelligence has a specific centre in the brain and neural system and is associated with a particular type of giftedness (e.g. mathematical giftedness) but is often demonstrated in combination with other intelligences (e.g. mathematical intelligence works alongside linguistic intelligence to understand a word mathematical problem). Recent brain studies have confirmed the existence of distinct centres in the brain and suggest that it is the ability of those centres to collaborate which determines the demonstrated level of giftedness (e.g. Just \& Varma, 2007). These views are supported by other modern conceptions of giftedness and talent development (e.g. Gagne 2008; 2011; Renzulli 1999; 2012; Sternberg 2003; 2010 Sternberg and Grigorenko 2002), which agree that there are individuals with natural abilities ("gifts") in different areas or activities (e.g. mathematics, languages, music, arts, leadership, interpersonal relationships, etc.), and that these abilities develop differently for different individuals in different circumstances. The extent to which they do or do not develop depends on the opportunities available, the culture and beliefs shaping the environment, the quality of interactions with others and the learner's motivation (e.g. "task commitment" according to Renzulli [1999, 2012]). When a natural ability or gift is not developed, underachievement occurs. Gagne's (2008) "Differentiated Model of Giftedness and Talent” represents this idea very well. According to Gagne, both intrapersonal and environmental factors are considered "catalysts" that may hinder or amplify a potential. In an educational setting, the school environment, the teachers and the peers can become the "catalysts" for developing or hindering mathematical potential. There are many able but underachieving students, as well as many more whose potential is hidden due to unfavourable environments and conditions (Ford 2003), which highlights the role of the school environment and the experiences within it. 
International literature from the gifted education field primarily concerns two key issues: early identification of giftedness and suitable educational provision for its development. In gifted literature, the issue of identifying truly gifted students has been highlighted as a problem caused by either focusing on intellectual giftedness or looking at demonstrated talents (in school mathematics this means standardised achievement test results). By doing this, we ignore creative giftedness and potential, as well as other important life skills, such as spatial and interpersonal skills (Sternberg and Grigorenko 2002; Renzulli 2012; Sternberg, Jarvin, and Grigorenko 2011). We also tend to ignore the fact that high-ability students do not comprise a homogeneous group. There is a range of ability within this group, with "exceptionally able" comprising only a very small percentage (one out of 10,000 being "exceptionally" able and one out of 100,000 being "extremely" able according to Gagne 1998). There can also be high ability combined with a range of diverse needs, including psychological needs like perfectionism, anxiety, depression (Speirs Neumeister 2007), and learning disability, as well as social needs like twice-exceptional students (Foley-Nicpon, Assouline, and Colangelo 2013). If we do not recognise these diverse abilities and needs, then we cannot effectively address them or successfully aid those exceptional individuals in reaching their fullest potential. It is suggested that early identification of a specific ability like mathematics requires a range of sources and methods. These could include a combination of tests (e.g. intelligence quotient [IQ], cognitive, achievement and nonverbal tests), as well as other assessment forms, including student portfolios, on-task observations (Gardner 1999; 2006; Karolyi, Ramos-Ford, and Gardner 2003; Renzulli 1999; Sternberg 2003; VanTasselBaska, Feng, and Evans 2007), and other "atypical" measures (Kell, Lubinski, and Benbow 2013). However, with mathematics, using other methods beyond standardised tests requires understanding the ability pattern, as well as the differences in the nature of development among individuals with profound intellectual ability (Kell, Lubinski, and Benbow 2013) and the attributes of mathematical ability (Dimitriadis 2016; Eyre 2001; Sheffield 1999; Koshy 2001). For the latter, the use of a characteristics list of mathematically promising students, like the one developed by Sheffield (2003), can be useful. However, Sheffield (2003) recommends that such a list itself cannot be effective without specialised knowledge and training for teachers of gifted students.

The results of an ongoing longitudinal Study of Mathematically Precocious Youth (SMPY) show that identifying true mathematical potential early, followed by differential development, can predict extraordinary scientific accomplishments in the future (Kell, Lubinski, and 
Benbow 2013; Lubinski and Benbow 2000; 2006; Lubinski, Benbow, and Kell 2014). However, a universally accepted answer has not yet been found for the issue of differential development, nor for the best way that this can be achieved. This is mainly because, despite the plethora of educational models for programmes aimed at gifted pupils, there is no strong empirical evidence from classroom practice indicating what works well in the long term (Plucker and Callahan 2014). Additionally, 'giftedness' has no universally accepted definition. What's more, the special provision measures adopted by schools often lack support from gifted theory and research, thus reducing consistency between identification, instruction, and evaluation (Renzulli 2012; Sternberg, Jarvin, and Grigorenko 2011). The latter deficiency has generated strong criticism for gifted education, as well as anything labelled as "gifted" (Borland 1996, 2013), and has led to ambitious attempts for gifted policy development ending in failure (e.g. G\&T initiative in England and Wales [Dimitriadis 2016]). Gifted education advocates suggest that a gifted programme or special measure can only be successful under certain conditions, namely: enriched training for educators; clear and challenging excellence goals; selective access criteria; systematic and regular practice; regular and objective progress assessment; personalised pacing (Gagne 2011); and learning opportunities not already available to the selected students (Stanley 2000; Renzulli 2012).

In mathematics education, there are frameworks for teaching mathematically able children that emphasise depth and challenge (Casey 1999; Koshy 2001; 2002; Koshy, Ernest, and Casey 2009; Schoenfeld 1992; Sriraman 2003). However, this does not necessarily mean that these frameworks can fully address the needs of exceptionally able mathematicians that are in the top percentage of the ability continuum (Gagne 1998) and are capable of learning advanced mathematical content at a faster pace (Sheffield 1999). Sheffield and SMPY researchers (Lubinski and Benbow 2006; Lubinski et al. 2001; Muratori et al. 2006) suggest that these exceptionally able children require different learning opportunities (e.g. deeper and more abstract material) in order to reach their potential, as well as a change of pace (acceleration).

\section{Methods}

In June 2015, an electronic questionnaire was distributed to 622 primary schools within four southwest England LEAs. This was a large number for a pilot study, but the hope was to 
ensure a good number of responses within a short time period (a month before the school year ended); a target of approximately 30 schools and 50 practitioners from all four LEAs was considered appropriate for this pilot. The aim was to gather insights from a small number of schools regarding their practices, as well as the teachers' views and perceived needs. This would help to identify trends in schools' and classroom teachers' practices regarding educating able mathematicians, as well as possible needs and/or gaps between theory/research and practice. Additionally, this would offer insights into the feasibility of a larger-scale study.

The questionnaire consisted of two main parts: the Head Teacher's Questionnaire and the Classroom Teacher's Questionnaire. The former collected information about the school, its policy and practice, and the school leader's views. The latter collected data about classroom practice, along with the classroom teacher's knowledge, beliefs and needs. Participants had a third option where they could choose to complete both questionnaires if they were both head teachers and classroom teachers within their schools. The questionnaire was addressed to the head teacher, who was asked to complete the relevant questionnaire and to forward the invitation, the Participant Information Sheet and the electronic questionnaire link to all of their classroom teachers and ask them to complete the Classroom Teacher's Questionnaire. The questionnaire had both closed (e.g. multiple choice and rating scales) and open questions, adding a qualitative element to the research, which is important when investigating educational issues (Hitchcock and Hughes 1995; Miles, Huberman, and Saldaña 2014). The questionnaire was tested (piloted) twice with practicing teachers (both head and classroom teachers) who worked in schools from the researchers' university partnership scheme. After each test, small changes were made regarding clarity, mandatory versus optional questions, and technical issues (e.g. question order) before it was distributed to the schools. Because of the low response rate (32 responses after a week), a reminder was sent after two weeks, which increased the number to 50 responses from 29 schools. One of the respondents (a school administrator) only filled in the school information, e.g. the school type, the area and the number of pupils. This response was removed, and the remaining 49 were analysed. These included: 20 from the Head Teacher's Questionnaire, 21 from the Classroom Teacher's Questionnaire, and eight from both questionnaires. This means that 28 responses referred to school policies/practices and the views and perceived needs of school leaders (heads or acting heads). A total of 29 responses represented teachers' (both head and classroom) practices, views and perceived needs. 
Open question data were analysed thematically and categorised under common themes. All respondents were given a coding name based on the questionnaire that they answered and the order in which their response was recorded. For example, the first response from the Head Teacher's Questionnaire was given the code name "HEAD 1", while the first response from the Classroom Teacher's Questionnaire received the code name "TEACHER 1", and the first response from both questionnaires was given the code name "HEAD \& TEACHER 1". This was helpful for comparing and categorising the open questions. The Likert scale data were analysed using descriptive statistics.

\section{Results}

\section{Schools' Policy and Practices}

The school practices findings are based on the Head Teacher's Questionnaire responses, representing situations in 28 different schools. Head (or acting head) teachers' responses showed interest in the education of pupils who are highly able or gifted in mathematics. A total of 24 out of 28 respondents said that their schools were implementing some form of provision for highly able or gifted pupils within regular mathematics classrooms, with or without having a specific policy for that. Of these 24 respondents, 15 answered that they had a "specific policy of provision" for their mathematically able or gifted students (Table 1).

Table 1. Schools' measures/policies of provision for mathematically able/gifted children

$n=28$ (schools)

\begin{tabular}{lc}
\hline Answer Options & Response Rate \\
\hline Taking measures for mathematically able/gifted children with or without having a & 24 \\
specific policy & 15 \\
Specific policy of provision for highly able/gifted pupils in mathematics & 4 \\
Policy is part of SEND policy & 5 \\
Policy is part of a G\&T policy & 7 \\
The maths coordinator oversees provision & 6 \\
The G\&T coordinator oversees provision & 2 \\
The Head or Deputy Head oversees provision & 0 \\
Evidence of theory/model to underpin the policy & \\
\hline
\end{tabular}

Teachers' responses also revealed that a small number of schools (five) maintained a separate G\&T policy, part of which was their provision for gifted mathematicians, while some schools 
included this provision as part of their Special Educational Needs and Disability (SEND) policy (four). Where there was a specific policy for most able mathematicians, the person overseeing said provision varied from mathematics coordinators (seven) to G\&T coordinators (six), or even a head/deputy head (two).

Thirteen participants (from 28 schools) responded that their schools did not have a specific provision policy. In general, the reasons offered for this response were the fact that there was no statutory policy for gifted or more able students (five) and the feeling that there was no need for such (five). Three participants did not explain their reasons, but others expanded on their answers explaining:

- Why there is no need for something specific: "[An] Able and Talented provision is woven in to all of our policies, each subject does not have a separate policy for Able and Talented" (HEAD 18).

- Their thoughts on and interest in establishing provision policies: "This [policy of provision] would be something that I would be interested in forming" (HEAD 16).

- Their concerns about how to convert a policy into practice: "You could have policies for everything and the reality is that policy doesn't convert to practice necessarily - a culture is more important" (HEAD 7).

\section{Identification Methods}

Table 2 presents the methods used by the schools for identifying highly able or gifted mathematicians. Analysis showed that schools primarily used two methods: teacher nominations (20 out of 28) and National Curriculum referenced standardised achievement tests (18 out of 28). In three further schools, head teachers selected the "other" option. However, the explanation provided better fitted the "teacher nominations" option.

\section{Special Arrangements outside of the Regular Classroom - With or Without a Policy}

As mentioned earlier, with or without a policy for provision, 24 out of 28 schools were implementing practices for addressing highly able or gifted mathematicians' needs. A total of 
$18(64 \%)$ were using special arrangements outside of the regular classroom. These were mainly pull-out groups that were sometimes combined with a setting (see Table 3).

Table 2. Identification methods

\begin{tabular}{lc}
$n=28$ (schools) & Response Rate \\
\hline Answer Options & 20 \\
\hline Teacher nomination & 18 \\
Standardized achievement tests referenced by NC & 3 \\
Parent nomination & 3 \\
Other & 1 \\
Cognitive tests (e.g. CAT4 from GL Assessment) & 0 \\
IQ tests & 0 \\
Peer nomination & 0 \\
Self-nomination & \\
\hline
\end{tabular}

The 18 head (or acting head) teachers who stated that their schools were implementing special arrangements beyond the regular classrooms were asked for more information regarding: a) possible age/class boundaries of children's selection (from a single year group or several); b) the time allocated to them (part- or full-time measures); and finally, c) who teaches them. Responses to the first two questions are presented in Table 3, while responses to the third question, which were mainly open and coded and categorised, are presented in Table 4. Responses indicated that special arrangements were chiefly based on age, not ability; only seven out of 18 schools with special arrangements had pupils identified as highly able across year groups. Additionally, part-time solutions were the most common option (see Table 3; eight out of 18 participants from those schools responded to this question). The special classes were primarily taught by ordinary classroom teachers who, though interested in gifted education, did not have any special training for this (see Table 4). There were only a few cases where staff members or external staff with mathematics backgrounds were used. 
Table 3. Organisation of the special arrangements outside the regular classroom

\begin{tabular}{|c|c|c|c|c|c|c|}
\hline & Setting & $\begin{array}{l}\text { Pull-out } \\
\text { grouping }\end{array}$ & Other & $\begin{array}{l}\text { Pull-out } \\
\text { grouping } \\
+ \text { Setting }\end{array}$ & $\begin{array}{c}\text { Pull-out }+ \\
\text { Other }\end{array}$ & Total \\
\hline $\begin{array}{l}\text { Class/group for high achievers } \\
\text { from the same year group }\end{array}$ & 1 & 5 & 1 & 3 & 1 & 11 \\
\hline $\begin{array}{l}\text { Class/group of pupils } \\
\text { identified as more able } \\
\text { across year groups }\end{array}$ & 1 & 2 & 2 & 1 & 1 & 7 \\
\hline Total & 2 & 7 & 3 & 4 & 2 & 18 \\
\hline $\begin{array}{l}\text { Full-time special arrangement } \\
\text { (all days, all maths hours) }\end{array}$ & & 1 & & 1 & & 2 \\
\hline $\begin{array}{l}\text { Part-time special arrangement } \\
\text { (for particular days or hours) }\end{array}$ & & 2 & 1 & 2 & 1 & 6 \\
\hline Total & & 3 & 1 & 3 & 1 & 8 \\
\hline
\end{tabular}

Table 4. Who teaches the special classes?

\begin{tabular}{lc}
$n=28$ (schools) & Response Rate \\
\hline Coded and Categorised Answers & 8 \\
\hline Classroom teacher, member of staff with no special training & 3 \\
Classroom teacher, member of staff, with a mathematics background & 3 \\
External professional from a higher Key Stage (e.g. secondary school) & 2 \\
Classroom teacher and a teaching assistant, members of staff & 2 \\
No response & 2 \\
\hline
\end{tabular}

\section{Provision within the Regular Classroom - With or Without a Policy}

The head teachers whose schools were taking some provision measures for highly able or gifted pupils within the regular classroom (24 out of 28) were asked who was delivering this provision to pupils. Their responses, which are presented in Table 5, revealed that provision for able or gifted mathematicians within the regular classrooms was primarily delivered through the regular classroom teacher and a teaching assistant, or else the classroom teacher and a mathematics specialist (eight out of 28). A mathematics specialist was someone with a mathematics background (e.g. a mathematics course: "This year we had a math graduate from the University of Bristol work with our Year 6 children" [HEAD 2]). There was only one case where a gifted specialist was mentioned, but no further details were given (he/she might have been a G\&T coordinator). 
Table 5. Who delivers provision within the regular classroom?

\begin{tabular}{lc}
$n=28$ (schools) & Response Rate \\
\hline Answer Options & 10 \\
\hline The regular classroom teacher and teaching assistant(s) & 8 \\
The regular classroom teacher and a mathematics specialist & 5 \\
The regular classroom teacher & 4 \\
No response & 1 \\
The regular classroom teacher and a gifted specialist & \\
\hline
\end{tabular}

\section{Teachers' Profile and Practices}

The findings on teachers' practice are based on the 29 responses from the Classroom Teacher's Questionnaire.

\section{Teachers' Profile}

Table 6 presents a brief profile of the teachers who completed this questionnaire. Most of them were ordinary classroom teachers, but there were a significant number (13 out of 29) who taught in special classrooms for able mathematicians (top math sets or pull-out groups). A total of 17 teachers had an additional role. This role was primarily undertaken by a mathematics coordinator or a mathematics subject leader (10). There was only one teacher with additional responsibility for running a G\&T group for Year 6 pupils. A total of 21 teachers stated that they had some training in gifted education (seven), teaching mathematics to highly able or gifted children (10), or higher mathematics (four). When teachers shared their training details in response to an open question, their training appeared to involve mainly insets or staff development meetings. Next is a sample of their responses to the question "please provide details (e.g. when, what programme, provider, etc.)":

CPD [Continuing Professional Development] provided by [the] local teaching school. (TEACHER 2, math subject leader) 
Staff professional development meetings from G\&T coordinator. (TEACHER 9, ordinary classroom)

There was only one case where this training had links with university studies. In this case, it was a dissertation, as the following example shows:

[I] had some training with [name of the LA]. Also, my dissertation was based upon provision for G\&T primary aged pupils. (TEACHER 21, pull-out Y6 group)

Table 6. Teachers' profile

$n=29$ (participants with teaching responsibilities)

Training background

Teachers

In teaching mathematics to highly able/gifted students

In gifted education

In teaching higher mathematics (e.g. KS3 or higher)

Role in school - class responsibility

Ordinary classroom

Maths set, part of a setting programme

Pull-out group for more able students

Planning Preparation Assessment (PPA) responsibility in the Nursery

Maths coordinator/subject leader

Role in school - other responsibility

Assessment for learning

\section{Teachers' Practices}

Use of ability-grouping and extra teaching materials. Most classroom teachers used abilitygrouping arrangements in their mathematics classes (23 out of 29), either in every lesson (16) or occasionally (seven). Most also used extra teaching materials beyond the usual (20 out of 29) (see Table 7). These materials were found primarily through free online sources (e.g. Nrich or TES), while a few schools used commercial publications or programmes (see Table 8). 
The teachers explained that the activities they used from those sources were mainly for adding depth or enhancing understanding, rather than for accelerating more able pupils:

Activities that broaden understanding rather than necessarily taking them to a higher level. (TEACHER 2, math subject leader)

Further steps, quirky number patterns and tricks, extended geometry. (TEACHER 6, ordinary classroom)

Work appropriate for the age, including open-ended problem solving activities.

(TEACHER 17, top mathematics set)

Use of a particular approach or framework. The teachers were also asked whether they used an approach or framework specifically designed for teaching able or gifted mathematicians. There were five teachers who answered "yes" (Table 7), but their explanations indicated that they simply meant extra activities that were used for extension rather than a specific approach or framework recommended by theory and research. Next is a sample of what those teachers meant as "a particular approach or framework for teaching able or gifted mathematicians":

Extension activities. (TEACHER 1, math coordinator)

With older children, [I] teach to KS3 [Key Stage 3, secondary education] expectations. (HEAD \& TEACHER 2, pull-out group)

I have a set of Level 6 questions for each topic that I go through each week. Level 6 Rising Stars for Math. (HEAD \& TEACHER 3, pull-out group)

[The] MEP [mathematics enhancement programme] more able challenges booklet “Child as Teacher". (TEACHER 16, ordinary classroom)

A small number of teachers did not use any extra teaching materials for mathematically highly able or gifted pupils (see Table 7). This was because there was no time for such during the lessons (TEACHER 19, ordinary classroom), or else because: "It is hard to find resources that some children can access independently when there is a class of 30 to cater for" (TEACHER 4, ordinary classroom). 
Table 7. Teachers' working style regarding the teaching materials, grouping arrangements and framework that guides their methods

$n=29$

\begin{tabular}{lc}
\hline Answer Options & Response Rate \\
\hline $\begin{array}{l}\text { Teachers use extra teaching materials for particular groups or individuals } \\
\text { beyond what is usually used, which involve... }\end{array}$ & 20 \\
- Advanced work from the higher levels of mathematics syllabus & 12 \\
- Work selected by the students themselves & 2 \\
- Work appropriate for their age but different from usual & 6 \\
$\begin{array}{l}\text { Don't use extra teaching materials } \\
\text { Use grouping arrangements in their mathematics class... }\end{array}$ & 6 \\
- In every lesson for particular tasks & 23 \\
- In every lesson for the whole lesson & 13 \\
- Occasionally for particular tasks & 3 \\
- Occasionally for the whole lesson & 7 \\
$\begin{array}{l}\text { Use a particular approach or framework for teaching able or gifted } \\
\text { mathematicians }\end{array}$ & 0
\end{tabular}

Table 8. Sources used to find materials for mathematically able pupils

$n=29$

\begin{tabular}{lc}
\hline Answer Options & Response Rate \\
\hline Nrich & 16 \\
TES & 9 \\
Internet search & 7 \\
Commercial publications (e.g. BEAM, Hamilton Trust) & 4 \\
National Curriculum sources (e.g. DfE, QCA) & 3 \\
Own sources & 1 \\
Testbase & 1 \\
NCETM & 1 \\
\hline
\end{tabular}

Recognising pupils who are mathematically highly able or gifted. Classroom teachers' responses confirmed those from head teachers about relying on standardised achievement tests (23 out of 29). There was only one mention of using IQ or cognitive tests. Classroom 
teachers were also asked to rate the effectiveness of some known identification methods using a four-point Likert-type scale (0-3) ranging from "not" to "very" effective. The results (see Table 9) revealed that they considered student's "performance on class work" (mean = 2.5 , mode $=3$ ) to be the most effective method for recognising high mathematical ability. This was followed by "performance on class tests" (mean = 2.15) and "standardised tests" (mean $=2.12)$. The lowest ranked methods were IQ and cognitive tests, followed by nominations from self, peers or parents.

Table 9. How effective the following identification methods are

\begin{tabular}{|c|c|c|c|c|c|c|c|}
\hline & Very & Moderately & Slightly & No & & & \\
\hline Answer Options & $(\%)$ & $(\%)$ & $(\%)$ & $(\%)$ & Mean & Mode & SD \\
\hline $\begin{array}{l}\text { Standardised achievement tests } \\
\text { (SATs) }\end{array}$ & 23.1 & 65.4 & 11.5 & 0.0 & 2.12 & 2 & 0.59 \\
\hline IQ tests & 7.7 & 42.3 & 38.5 & 11.5 & 1.46 & 2 & 0.81 \\
\hline Cognitive tests & 11.5 & 38.5 & 42.3 & 7.7 & 1.54 & 1 & 0.81 \\
\hline Performance on class tests & 30.8 & 53.8 & 15.4 & 0.0 & 2.15 & 2 & 0.67 \\
\hline Performance on class work & 57.7 & 34.6 & 7.7 & 0.0 & 2.50 & 3 & 0.65 \\
\hline Behaviour in classroom & 30.8 & 34.6 & 23.1 & 11.5 & 1.85 & 2 & 1.01 \\
\hline Out-of-classroom activities & 15.4 & 50.0 & 34.6 & 0.0 & 1.81 & 2 & 0.69 \\
\hline Parental nominations & 7.7 & 30.8 & 57.7 & 3.8 & 1.42 & 1 & 0.70 \\
\hline Peer nominations & 11.5 & 26.9 & 53.8 & 7.7 & 1.42 & 1 & 0.81 \\
\hline Peer relationship & 11.5 & 23.1 & 57.7 & 7.7 & 1.38 & 1 & 0.80 \\
\hline Self-nominations & 11.5 & 23.1 & 61.5 & 3.8 & 1.42 & 1 & 0.76 \\
\hline
\end{tabular}

\section{Practitioners'Perceptions, Views and Perceived Needs}

This section presents the answers gathered from all three parts (Options 1, 2, and 3) of the questionnaires completed by head (or acting head) teachers and classroom teachers. These participants were asked to express their views and thoughts about: (i) how challenging it is to 
make provision for particular populations, including low-, middle- and higher-ability students, along with higher-ability with SEND students; (ii) what practice from their school provision works best; (iii) their confidence in teaching particular populations, including low-, middle- and higher-ability students, along with higher-ability SEND students; (iv) how they feel when they have highly able or gifted mathematicians in their class; (v) whether they feel that they need more support and training, and if so, in what area; (vi) any other thoughts regarding those students' education; and finally, (vii) their interest in participating in a follow-up interview. Only head teachers (and those acting as a head) were asked the first two questions. Classroom teachers and head teachers with a classroom were asked the third, fourth and fifth questions. Everyone was asked the sixth and seventh questions. There were additional questions investigating participants' experiences working with gifted underachievers, as well as their knowledge, experience and confidence in recognising and working with twice-exceptional mathematics students, but these will be presented in a separate article. Findings from the seven questions are now presented thematically.

Table 10. Head teachers' views about how challenging is to make provision

\begin{tabular}{|c|c|c|c|c|c|c|c|}
\hline & Very & Moderately & Slightly & No & & & \\
\hline Answer Options & $(\%)$ & $(\%)$ & $(\%)$ & $(\%)$ & Mean & Mode & SD \\
\hline Lower ability students & 9.52 & 42.86 & 42.86 & 4.76 & 1.57 & 2 & 0.75 \\
\hline Middle ability students & 0.00 & 38.10 & 38.10 & 19.05 & 1.14 & 2 & 0.79 \\
\hline Higher ability students & 4.76 & 42.86 & 47.62 & 0.00 & 1.48 & 1 & 0.68 \\
\hline Higher ability with SEND & 14.29 & 38.10 & 38.10 & 0.00 & 1.57 & 2 & 0.87 \\
\hline
\end{tabular}

Making Provision for and Teaching Children with a Range of Mathematics Abilities and Needs

The head teachers' first question was on a four-point Likert-type scale (0-3) ranging from "not" to "very" challenging. This question's responses (see Table 10) indicated that the options at the two extremes ("lower-ability" and "hHigher-ability with SEND") were 
considered the biggest challenges by head teachers. The mean was closer to two on the scale (Moderately challenging), with the "higher-ability students" option ranking between two and one. However, the "higher-ability with SEND" option had the most responses at the highest point on the scale (Very challenging). All of the responses relating to higher-ability students, with or without SEND, were positioned on points on the scales with a level of challenge; these two options had zero in the "not" challenge question.

Table 11. Head teachers' views about what works best

\begin{tabular}{|c|c|c|c|c|}
\hline Coded and Categorised & 3 & 2 & 1 & \\
\hline & 1st Best & 2nd Best & 3rd Best & Score \\
\hline Ability grouping/small grouping & 3 & 1 & & 11 \\
\hline Working with a maths specialist & 2 & 2 & & 10 \\
\hline Pull-out grouping & 3 & & & 9 \\
\hline Additional challenge & 2 & 1 & 1 & 9 \\
\hline Differentiated work & 1 & 2 & 1 & 8 \\
\hline Teacher's assessment \& Standardize tests & 2 & 1 & & 8 \\
\hline HOT, problem solving, critical thinking & 1 & 2 & 1 & 8 \\
\hline Specialist provision & 1 & 2 & 1 & 8 \\
\hline LTHC/investigations & 2 & & 1 & 7 \\
\hline Special maths sessions/events/clubs & & 2 & 3 & 7 \\
\hline Individual/additional support & 1 & & 1 & 4 \\
\hline Other & 1 & & & 3 \\
\hline
\end{tabular}

Head teachers were then asked to list the most effective practices that their schools were using, as well as to rank those practices from one to three, with one as the best. These responses were analysed thematically and categorised based on common themes. A total of 12 categories (including the option "other") were created (see Table 11). Three answers fell into two categories (e.g. "Differentiated work" and "Working with a math specialist") and 
these answers were included in each of the appropriate categories. The participants' first- to third-best method rankings were subsequently graded from three to one (see Table 11), which was multiplied by each answer's frequency, thus scoring each of the methods considered by head teachers as the best for meeting mathematically highly able students' needs. The answers that scored most highly were those about using small ability groups, working with a mathematics specialist, using pull-out groups and introducing additional challenges. The answers that most participants ranked one were those referring to small ability groups and pull-out groups. Working with a math specialist was also highly rated (Table 11).

Table 12. Teachers' confidence in teaching mathematics to pupils with a range of mathematical ability and needs

\begin{tabular}{|c|c|c|c|c|c|c|c|}
\hline & Very & Moderate & Slight & No & & & \\
\hline Answer Options & $(\%)$ & $(\%)$ & $(\%)$ & $(\%)$ & Mean & Mode & SD \\
\hline Lower ability students & 36.0 & 60.0 & 4.0 & 0.0 & 2.32 & 2 & 0.6 \\
\hline Middle ability students & 64.0 & 32.0 & 4.0 & 0.0 & 2.60 & 3 & 0.6 \\
\hline Higher ability students & 44.0 & 52.0 & 4.0 & 0.0 & 2.40 & 2 & 0.6 \\
\hline Higher ability with SEND & 24.0 & 52.0 & 20.0 & 4.0 & 1.96 & 2 & 0.8 \\
\hline
\end{tabular}

Confidence in Teaching Mathematics to Pupils with a Range of Mathematical Ability and Needs

The third and fourth questions, which related to teaching, were addressed to practitioners who had a class (classroom teachers and head teachers with teaching responsibilities). The third question used a four-point Likert-type scale similar to the one used for the heads, but this time asking about teachers' confidence in teaching mathematics to (instead of making provision for) pupils with a range of abilities and needs. Analysing the teachers' responses (Table 12) revealed generally high confidence levels, especially for "lower-ability" and "middle-ability" pupils. The mean was just above "Moderate" for "Higher-ability students", and was below "Moderate" for "higher-ability with SEND", with 24\% of responses gathering around the lower end of the scale. The fourth question was a seven-point scale ranging from 
"very easy" to "extremely difficult", along with the option "no overall effect", for describing what they feel about teaching highly able or gifted mathematicians in their class. The responses (see Figure 1) showed that more teachers felt that this makes their work more difficult (40\%) rather than making it easier (32\%), while a sizeable number felt that this makes no difference (28\%).

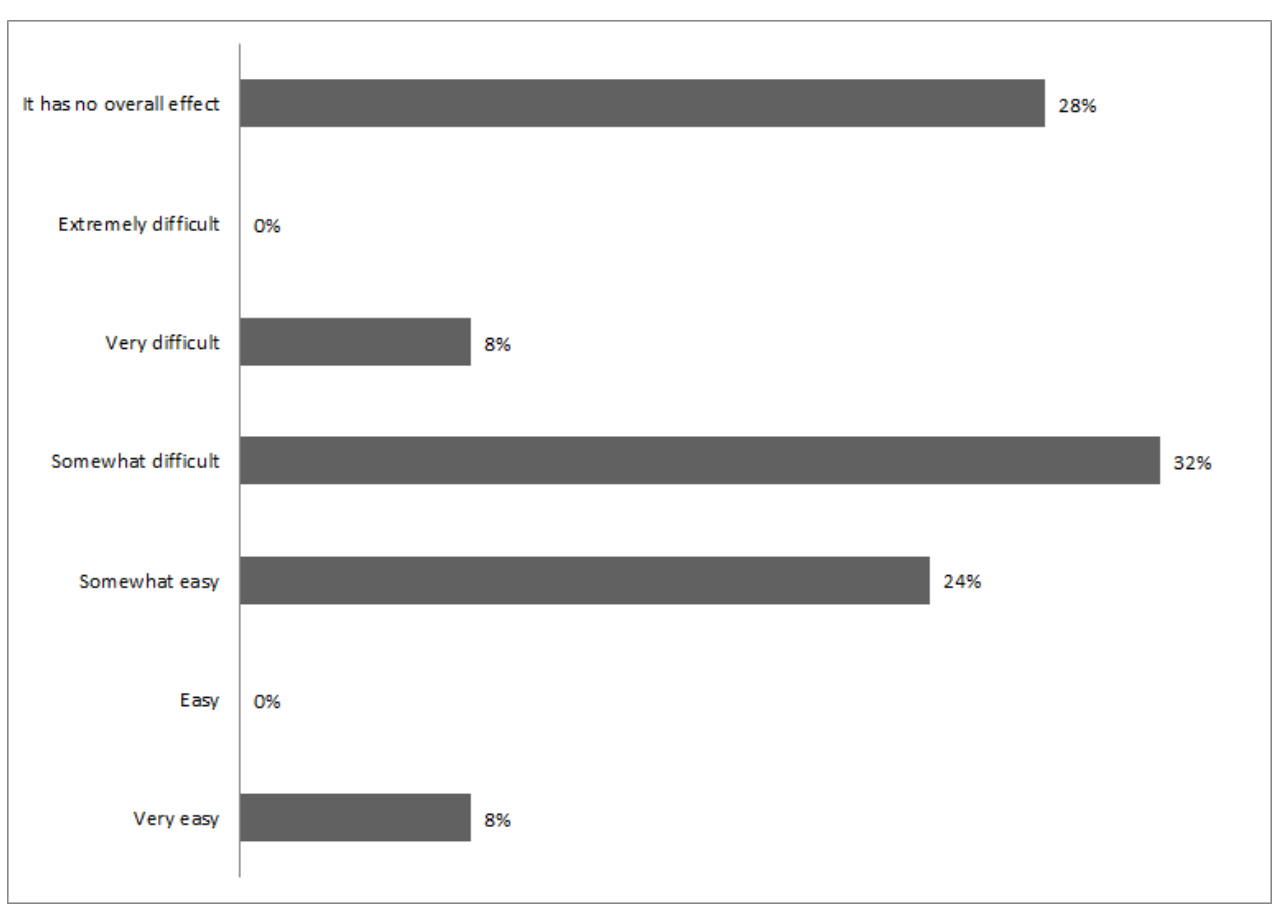

Figure 1. How teachers feel when they have some highly able/gifted mathematicians in their class

Perceived Needs and Open Thoughts

Responses to the fifth question showed that 18 out of 29 participants with teaching responsibilities felt that they need more support or training in order to address the needs of mathematically highly able or gifted students effectively, while a further three felt unsure about this. The areas where they felt that they needed more support and training were identified through a multiple choice question. These areas were primarily related to practicalities (e.g. teaching materials and organising provision and classroom differentiation). 
However, they were also related to recognising and understanding mathematical potential and creativity, along with understanding complex needs of gifted students (see Table 13).

Table 13. Areas in which teachers think that they need more support or training

\begin{tabular}{lc}
$n=29$ & \\
\hline Answer Options & Response Rate \\
\hline Teaching materials for more able mathematicians & 15 \\
Organising provision and classroom differentiation & 12 \\
Understanding the student with mathematical potential and creativity & 11 \\
Recognising high ability in special populations (e.g. twice-exceptional) & 11 \\
Assessment & 8 \\
Knowledge of higher mathematics (e.g. KS3 or higher) & 7 \\
Other & 0 \\
\hline
\end{tabular}

The sixth question asked all who had teaching responsibilities to provide their open thoughts on educating highly able or gifted mathematics students. The participants highlighted concerns including the influence of the new national curriculum and the "mastery" initiative, along with providing suggestions for further training and resources:

- The new national curriculum's influence: “The new curriculum requires that everybody learns at the same rate, and moves through the content at the same pace. This is unrealistic, and I worry about how to stretch the most able without moving them on to new material. There is only so much lateral movement before children will become frustrated. This year I had 10 year 6 pupils, and my SAT results in Math were 2 level 3s, 2 level 4s, 4 level 5s and 2 level 6s. It would have been very difficult to have taught these children effectively as the new approach requires" (TEACHER 1, math coordinator).

- The "mastery" initiative's influence: "The needs of able pupils are being overlooked with the new style assessment system which supports mastery, as I feel this will slow learning for some pupils and could demotivate [them]. The provision for more able [students] is critical and essential to good inclusion. The "habits" of the profession and society often don't acknowledge the needs of this group both academically and emotionally" (HEAD 15). 
"I'm currently concerned about the ceiling being lowered upon gifted mathematicians in primary schools where "mastery" is the byword. There are only so many ways one can "enrich" a gifted pupil when they are straining on the leash to explore mathematics from a higher key stage” (TEACHER 21, pull-out Y6 group).

- Need for more training and resources: "More training and resources need to be available, especially when teaching mixed age classes" (HEAD \& TEACHER 1).

"Teachers are needing to become more highly qualified and able in math themselves in order to appropriately challenge [their students]. Schemes such as MEP support staff development, but more INSET [in-service training] is needed" (HEAD 16).

Interest in Participating in a Follow-Up Interview

Eight of the respondents (16\%) expressed interest in participating in a follow-up interview. Half of them were classroom teachers, while three were head teachers and one was a head teacher with teaching responsibilities.

\section{Discussion}

With the G\&T initiative being dropped, along with the recent changes in England's national curriculum, this pilot study aimed to investigate in primary schools: (a) whether there is interest in the education of children who are able or have the potential to highly excel in mathematics; (b) whether educational measures are taken for those children, and if so, what these entail; and (c) teachers' views, experiences, and perceived needs. This pilot's ultimate aim was to understand whether and what further research is needed to support school practice recognising and developing mathematical potential. Findings in relation to these aims, will now be discussed, along with other issues that emerged.

\section{Interest and Policy Implications}


This study found an interest in educating mathematically highly able pupils, as most of the participating schools do take some measures for such children even though they are not required to follow a specific statutory guidance. This result was not surprising, as taking measures to address more able pupils' needs is one of the government's requirements, as expressed through Ofsted's documents $(2013 ; 2014 ; 2015 a ; 2015 b)$. What is surprising is that, despite the G\&T initiative being dropped, some schools still have G\&T policies and coordinators, even though this is no longer a requirement. It seems that schools recognise both a real need and a gap in current educational policy, which they try to fill with elements of the no longer active G\&T policy. This need and gap are reflected in a head teacher's response expressing an interest in developing their own gifted policy.

The freedom and encouragement provided by the government for educators to find by themselves what works well and to implement it in their practice provides opportunities for local initiatives (Department for Education 2016). However, this cannot ensure that the critical question of how to recognise and fulfil true potential will be addressed. Busy practitioners and leaders could find it easy to rely on practices recommended by non-credible and questionable sources, which is not uncommon (Renzulli 2012; Ambrose et al. 2010). Additionally, the fact that there is no statutory requirement for having a higher able and gifted student policy has left a number of teachers believing that there is no need for any such policy, making it unlikely that these practitioners will begin doing something on their own.

Schools meeting academically gifted children's needs cannot be left solely up to practitioners' initiative and good will; this requires political changes and a reform of new rules, standards, and regulations (Gallagher 1975; 2015), as well as a clear educational policy for gifted learners (Coleman, Gallagher, and Job 2012; Gallagher 2015). Although a gifted policy cannot promote academic excellence by itself, it can increase consistency, make the measures less random (Dimitriadis 2016), and create the basis for developing suitable and supportive learning environments for academically gifted students (Coleman, Gallagher, and Job 2012; Gallagher 2015). To achieve this, more and continuous research into applying gifted education models and innovations is needed in order to discover what works well for mathematically promising pupils, as well as what offers the best fit to inform policy and practice within the British education system and culture. Our participants' interest in learning from this study, as well as in taking part in follow-up interviews, clearly supports this need. 


\section{Educational Measures}

This study found that most of the participating schools use special arrangements outside of the regular classroom for pupils identified as more able or gifted (i.e. pull-out groups and setting, sometimes combined). These arrangements were similar to those found by previous research. They were also organised in a similar way, which has been found to be random and failing to truly match gifted students' needs (Dimitriadis 2012). The identification methods were mainly based on teacher nominations, which were drawn from teachers' informal tests and observations, as well as standardised achievement tests. Both of these methods ignore intelligence, which is an essential component of giftedness (Gagne 2008; 2011; Gardner 1999; Renzulli 1999; 2012; Sternberg 2003; 2010; Sternberg and Grigorenko 2002). They also cannot alone identify every aspect of ability, which is multifaceted (Ibid), even when this is not disguised by a learning disability (twice-exceptionality), which makes identification even more challenging (Koshy 2001). In addition, teacher observations cannot be accurate without specialised knowledge and using some methodology, such as rating scales (e.g. Pfeiffer and Jarosewich 2007; Ryser and McConnell 2004; Renzulli et al. 2010) or characteristics lists (e.g. Krutetskii 1976; Sheffield 2003). The findings show that teachers' most highly valued and commonly used identification method is their own assessment, which is based on children's class work and test performance. This highlights the importance of specialised knowledge for teachers of mathematically promising pupils.

Special arrangements for higher achievers were found to offer something different from the norm, which pragmatically responds to Ofsted's (2014) requirement for taking measures for the most able pupils. This agrees with previous findings (Dimitriadis 2012; Koshy, PinheiroTorres, and Portman-Smith 2012), but does not necessarily mean that it is the most appropriate provision. As highlighted by the literature, learning opportunities that differ from the norm may be interesting and useful for highly achieving children, but they are not enough for those who are exceptionally able, or those that have the potential to excel at a greater level and to make a difference in the future (Dimitriadis 2016; Sheffield 1999; Gagne 2011; Kell, Lubinski, and Benbow 2013). These students need reliable identification and systematic provision that meet the conditions set by gifted education literature (e.g. Gagne 2011; Stanley 2000; Renzulli 2012). Beyond this, they need support from well-trained teachers in both gifted education and mathematics (Sheffield 1999). This study found no evidence of such conditions, apart from some involvement of teachers with a measure of training in G\&T 
education or in teaching mathematics to able children in some schools implementing pull-out groups. As in previous research (Dimitriadis 2012; 2013), pull-out groups were found to offer some opportunities considered appropriate for mathematically able children (i.e. challenges and teachers with a specialism). However, as there was no theoretical underpinning, it would be important to see how schools evaluated their methods. This requires further research involving in-depth study of their practices.

An essential educational measure is having a gifted education-trained coordinator organising and overseeing provision for mathematically promising pupils, as well as acting as the first line of reference for staff members that need guidance and support when they face challenges (Koshy 2001; Koshy et al. 2012). However, the findings reveal a decline in the number of schools using such professionals (six or 21\%) compared to previous research (e.g. Dimitriadis [2013] 82\%, and Koshy, Pinheiro-Torres, and Portman-Smith[2012] 67\%). These findings, combined with the fact that up to this point the training that some teachers had received was offered as part of the G\&T programme that no longer exists, suggest that, if nothing changes, teachers with gifted training backgrounds who would be able lead provision for highly promising mathematicians will disappear from our schools in the coming years. This is not encouraging for the future.

\section{The Views, Experiences and Perceived Needs of School Leaders and Practicing Teachers}

Research that took place during the G\&T initiative found that, despite the familiarity that some teachers had with gifted education, more support and specialised training were still required in order to address mathematically able children's needs more effectively (Dimitriadis 2016; Brady and Koshy 2014). This study confirmed this need. Furthermore, this research found an increased percentage of teachers who felt that they needed this support or training (72\%, or $84 \%$ if we include those who stated "not sure") compared to previous research (64\%, Dimitriadis [2013]). What is interesting is that teachers continue to prioritise the same areas where they feel that they need this support or training (i.e. teaching materials for more able mathematicians, as well as organising provision and classroom differentiation). However, the percentages within the groups are now higher ( $83 \%$ and $67 \%$, respectively) compared to previous research (52\% and 45\%, respectively, Dimitriadis [2013]). Additionally, this research found that making provision for and teaching highly able 
mathematicians are considered challenging, especially when combined with special educational needs, known as "twice-exceptionality" (Assouline and Foley-Nicpon 2007; Foley-Nicpon, Assouline, and Colangelo 2013; Reis, Baum, and Burke 2014). This suggests that specialised support, training and guidance would be greatly welcomed by practitioners. It also shows a need for research in the area of support for twice-exceptionality.

\section{Other issues emerging in this study}

The special educational needs coordinator's (SENCO's) role

Questionnaire respondents were head teachers, deputy head teachers, acting head teachers, classroom teachers, and teachers with an extra role teaching able mathematicians, or else having a math coordinator's role. There were no responses from any special educational needs coordinators (SENCOs), even though the questionnaire was addressed to all school staff. One reason for this could be the questionnaire's title, which did not indicate special needs. However, it is interesting that there was no response from any SENCOs, even from schools claiming that their gifted policy was part of their SEND policy (which is overseen by the SENCO). It would be interesting to see SENCOs' perceptions and thoughts regarding gifted or twice-exceptional pupils, and this should be a question explored by future research. There is internationally growing interest in the nature of twice-exceptionality, as well as the best ways to identify and provide for twice-exceptional students. This has led researchers from the fields of psychology and education to suggest that stronger collaboration is needed between gifted and special education specialists (Foley-Nicpon, Assouline, and Colangelo 2013).

\section{The mastery curriculum}

The children identified as more able mathematicians, apart from those working in pull-out groups with teachers with secondary mathematics backgrounds, experienced opportunities aimed at adding a bit more depth to things that they already knew, but not to something that would accelerate them. This is in line with the "mastery" idea (National Centre for Excellence in the Teaching of Mathematics 2014), which encourages depth rather than 
acceleration, even if there are students who can learn faster. However, this is not in line with literature from the field of gifted education in general, or of mathematics in particular. Modern giftedness theories (e.g. Gagne 2008; 2011; Gardner 1999; 2006; Renzulli 1999; 2012; Sternberg 2003; 2010; Sternberg and Grigorenko 2002) have left aside the old debate of enrichment versus acceleration, recognising the need for both. The longitudinal SMPY (Lubinski and Benbow 2006; Lubinski et al. 2001; Muratori et al. 2006) has concluded that exceptionally able learners need not only deeper and more abstract learning opportunities in order to reach their potential, but also a change of pace, which means acceleration. Therefore, ignoring the acceleration aspect of provision in order to adapt to the mastery initiative could mean insufficient and incomplete development of mathematics potential. This concern has also been highlighted by practitioners who felt that the mastery initiative lowered the ceiling for gifted mathematicians. Finding the golden balance between mathematics mastery and fulfilling mathematical potential seems to be both particularly relevant and challenging, requiring further and deeper study of classroom practice, along with direct links to the most recent and credible research from the fields of both mathematics and high-ability education.

\section{Conclusion}

Despite the small sample, which clearly is a limitation to the study, teachers' and school leaders' responses did reveal evidence of the current situation in primary schools regarding educating "most able" children in mathematics. Furthermore, the findings also revealed evidence of what teachers need in order to support these children within the current educational context, thereby providing a good foundation for further, larger and more systematic research. This study concludes that the education of children with the ability or potential to excel in mathematics has reached a crucial stage. The number of trained professionals who can organise, run and oversee provision for highly promising learners has begun to decline. There is an increasing tendency to move away from differentiation or a faster learning pace for fast learners, which is encouraged by new initiatives such as "mastery". School leaders are required to develop their own policies and plans for helping their most able students meet their potential, but they have to do so without a clear definition of this particular population and with no specialised support and training. They are also required to base their policy and practice on good, research-based examples, but again without any minimum guidance. This could result in reliance on some questionable practices 
recommended by non-credible sources. This study recommends that it cannot be left up to practitioners untrained in research to discover what works well in practice in a variety of settings and cultures. This is something that needs to be done through systematic research, the findings of which will inform policy-makers and school practice. This research should look at international models of gifted educational underpinned by theory and research, and provide evidence of their application, in order to learn more about what works well and understand what would best fit the British educational system and culture.

\section{Acknowledgements}

The authors thank colleagues from Plymouth University for technical assistance (Claudia Blandon) and critical support (Linda La Velle and Nick Pratt).

\section{Funding}

The research for this paper was financially supported by Plymouth University's Research Bidding Scheme (R1, June 2015).

\section{References}

Ambrose, Don, Joyce VanTassel-Baska, Laurence J. Coleman, and Tracy L. Cross. 2010. "Unified, Insular, Firmly Policed, Or Fractured, Porous, Contested, Gifted Education?" Journal for the Education of the Gifted 33 (4): 453-478.

Assouline, SG and M. Foley Nicpon. 2007. "Twice-Exceptional Learners: Implications for the Classroom." NAGC Communiqué Teaching for High Potential, Spring: 9-13.

Borland, James H. 1996. "Gifted Education and the Threat of Irrelevance." Journal for the Education of the Gifted 19 (2): 129-47.

Borland, James H. 2013. "Problematizing Gifted Education." In Fundamentals of Gifted Education: Considering Multiple Perspectives., edited by Carolyn M. Callahan and Holly L. Hertberg-Davis, 69-80. New York, NY: Routledge.

Boyes, Louise Comerford. 2004. Accelerated Learning: A Literature Survey. Bradford: Unit for Educational Research \& Evaluation, University of Bradford. 
Brady, Maggie and Valsa Koshy. 2014. "Reflections on the Implementation of the Gifted and Talented Policy in England, 1999-2011." Gifted Education International 30 (3): 254-262. Casey, Ronald. 1999. "A Key Concepts Model for Teaching and Learning Mathematics." Mathematics in School 28 (3): 13-14.

Casey, Ronald. 2002. "A Framework for Teaching Mathematically Promising Pupils." In Unlocking Numeracy: A Guide for Primary Schools, edited by Valsa Koshy and Jean Murray, 122-145. London: David Fulton.

Casey, Ronald and Valsa Koshy. 2013. "Gifted and Talented Education: The English Policy Highway at a Crossroads?" Journal for the Education of the Gifted 36 (1): 44-65.

Coleman, Mary Ruth, James J. Gallagher, and Jennifer Job. 2012. "Developing and Sustaining Professionalism within Gifted Education." Gifted Child Today 35 (1): 27-36.

Cox, June, Neil Daniel, and Bruce O. Boston. 1985. Educating Able Learners: Programs and Promising Practices. Austin: University of Texas Press.

Department for Children, Schools and Families. 2008a. Effective Provision for Gifted and Talented Children in Primary Education. London: Author.

Department for Children, Schools and Families. 2008b. Identifying Gifted and Talented Learners: Getting Started. Annesley: DCSF.

Department for Education. 2016. Educational Excellence Everywhere. Cm 9230 ed. England: Author.

Department for Education. 2014. The National Curriculum in England: Framework Document. July ed. London: Author.

Dimitriadis, Christos. 2012. "Provision for Mathematically Gifted Children in Primary Schools: An Investigation of Four Different Methods of Organisational Provision." Educational Review 64 (2): 241-260.

Dimitriadis, Christos. 2013. Developing Mathematical Giftedness within Primary Schools: A Study of Strategies for Educating Children Who are Gifted in Mathematics. Saarbrücken, Germany: LAP, Lambert Academic Publishing.

Dimitriadis, Christos. 2016. "Gifted Programs Cannot be Successful without Gifted Research and Theory: Evidence from Practice with Gifted Students of Mathematics." Journal for the Education of the Gifted 39 (3): 221-236.

Evans, L. 2010. "G\&T Policy 'inconsistent'." G\&T Update 72 (March): 1.

Eyre, D. 2001. "An Effective Primary School for the Gifted and Talented." In Curriculum Provision for the Gifted and Talented in the Primary School: English, Maths, Science and $I C T$, edited by D. Eyre and L. McClure, 1-27. London: NACE/David Fulton Publishers. 
Foley-Nicpon, Megan, Susan G. Assouline, and Nicholas Colangelo. 2013. "Twice-

Exceptional Learners: Who Needs to Know what?" Gifted Child Quarterly 57 (3): 169180.

Ford, D. 2003. "Equity and Excellence: Culturally Diverse Students in Gifted Education." In Handbook of Gifted Education, edited by Nicholas Colangelo and Gary A. Davis. 3rd ed., 506-520. Boston; London: Allyn and Bacon.

Freeman, Joan, Johanna Raffan, and Ian Warwick. 2010. Worldwide Provision to Develop Gifts and Talents: An International Survey. Reading, UK: CfBT Education Trust.

Gagne, F. 1998. "A Proposal for Subcategories within Gifted or Talented

Populations". Gifted Child Quarterly. 42 (2): 87-95.

Gagne, F. 2008. Building Gifts into Talents: Brief Overview of the DMGT 2.0. Montréal, Québec: Author.

Gagne, F. 2011. "Academic Talent Development and the Equity Issue in Gifted Education." Talent Development and Excellence, 3 (1): 3-22.

Gallagher, James J. 1975. "How the Government Breaks its Promises." New York University Quarterly 6 (4): 22-27.

Gallagher, James J. 2015. "Political Issues in Gifted Education." Journal for the Education of the Gifted 38 (1): 77-89.

Gardner, Howard. 1983. Frames of mind: The theory of multiple intelligences. New York, NY: Basic Books.

Gardner, Howard. 1999. Intelligence Reframed: Multiple Intelligences for the 21 st Century. New York: Basic Books.

Gardner, Howard. 2006. Multiple Intelligences : New Horizons in Theory in Practice.

Revised and updated ed. New York; London: BasicBooks; Perseus Running distributor. Hitchcock, Graham and David Hughes. 1995. Research and the Teacher: A Qualitative Introduction to School-Based Research. London; New York: Routledge.

House of Commons. 2010. The Gifted and Talented Programme: Oral and Written Evidence, edited by Children, School and Families Select Committee. February 1, 2010. London: The Stationary Office.

Just, Marcel Adam and Sashank Varma. 2007. "The Organization of Thinking: What Functional Brain Imaging Reveals about the Neuroarchitecture of Complex Cognition." Cognitive, Affective, \& Behavioral Neuroscience Cognitive, Affective, \& Behavioral Neuroscience 7 (3): 153-191. 
Karolyi, C., V. Ramos-Ford, and H. Gardner. 2003. "Multiple Intelligences: A Perspective on Giftedness." In Handbook of Gifted Education, edited by N. Colangelo and G. A. Davis. 3rd ed., 100-112. Boston: Allyn and Bacon.

Kell, Harrison J., David Lubinski, and Camilla P. Benbow. 2013. "Who Rises to the Top?

Early Indicators." Psychological Science 24 (5): 648-659.

Koshy, Valsa. 2001. Teaching Mathematics to Able Children. London: David Fulton Publishers.

Koshy, Valsa, Paul Ernest, and Ron Casey. 2009. "Mathematically Gifted and Talented Learners: Theory and Practice." International Journal of Mathematical Education in Science and Technology 40 (2): 213-228.

Koshy, Valsa and Catrin Pinheiro-Torres. 2013. ""Are we being De- Gifted, Miss?" Primary

School Gifted and Talented Co-Ordinators' Responses to the Gifted and Talented Education Policy in England." British Educational Research Journal 39 (6): 953-978.

Koshy, Valsa, Catrin Pinheiro-Torres, and Carole Portman-Smith. 2012. "The Landscape of Gifted and Talented Education in England and Wales: How are Teachers Implementing Policy?" Research Papers in Education 27 (2): 167-186.

Krutetskii, Vadim Andreevich. 1976. The Psychology of Mathematical Abilities in Schoolchildren ; Translated from the Russian by Joan Teller ; Edited by Jeremy Kilpatrick and Izaak Wirszup. Survey of Recent East European Mathematical Literature. Chicago ; London: University of Chicago Press.

Lubinski, David, Camilla P. Benbow, and Harrison J. Kell. 2014. "Life Paths and Accomplishments of Mathematically Precocious Males and Females Four Decades Later." Psychological Science 25 (12): 2217-2232.

Lubinski, David and Camilla Persson Benbow. 2000. "States of Excellence." American Psychologist 55 (1): 137-150.

Lubinski, David and Camilla Persson Benbow. 2006. "Study of Mathematically Precocious Youth After 35 Years: Uncovering Antecedents for the Development of Math-Science Expertise." Perspectives on Psychological Science 1 (4): 316-345.

Lubinski, David, Rose Mary Webb, Martha J. Morelock, and Camilla P. Benbow. 2001. "Top 1 in 10,000: A 10- Year Follow- Up of the Profoundly Gifted." Journal of Applied Psychology 86 (4): 718-729.

Miles, Matthew B., A. Michael Huberman, and Johnny Saldaña. 2014. Qualitative Data Analysis: A Methods Sourcebook. 3rd ed. Thousand Oaks: Sage Publications. 
Muratori, Michelle C., Julian C. Stanley, Lenhard Ng, Jack Ng, Miraca U. M. Gross, Terence Tao, and Billy Tao. 2006. "Insights from SMPY's Greatest Former Child Prodigies: Drs. Terence ("Terry”) Tao and Lenhard ("Lenny”) Ng Reflect on their Talent Development." Gifted Child Quarterly 50 (4): 307-324.

National Centre for Excellence in the Teaching of Mathematics. 2014. Mastery Approaches to Mathematics and the New National Curriculum. Sheffield: National Centre for Excellence in the Teaching of Mathematics.

Office for Standards in Education. 2009. Gifted and Talented Pupils in Schools. London: Author.

Office for Standards in Education. 2013. Annual Report 2012/13: South West Regional Report. London: Author.

Office for Standards in Education. 2014. The Report of Her Majesty's Chief Inspector of Education, Children's Services and Skills 2013/14: South West Regional Report. London: Author.

Office for Standards in Education. 2015a. The most Able Students: An Update on Progress since June 2013. No. 150034. London: Author.

Office for Standards in Education. 2015b. School Inspection Handbook: Handbook for Inspecting Schools in England Under Section 5 of the Education Act 2005 (as Amended by the Education Act 2011). No. 120101 ed. London: Author.

Pfeiffer, Steven I. and Tania Jarosewich. 2007. "The Gifted Rating Scales-School Form: An Analysis of the Standardization Sample Based on Age, Gender, Race, and Diagnostic Efficiency." Gifted Child Quarterly 51 (1): 39-50.

Plucker, Jonathan A. and Carolyn M. Callahan. 2014. "Research on Giftedness and Gifted Education: Status of the Field and Considerations for the Future." Exceptional Children 80 (4): 390-406.

Reis, Sally M., Susan M. Baum, and Edith Burke. 2014. "An Operational Definition of Twice-Exceptional Learners." Gifted Child Quarterly 58 (3): 217-230.

Renzulli, Joseph S. 1999. "What is this Thing Called Giftedness, and how do we Develop it? A Twenty-Five Year Perspective." Journal for the Education of the Gifted 23 (1): 3-54. Renzulli, Joseph S. 2012. "Reexamining the Role of Gifted Education and Talent

Development for the 21st Century: A Four-Part Theoretical Approach." Gifted Child Quarterly 56 (3): 150-159.

Renzulli, Joseph S., L. H. Smith, A. J. White, C. M. Callahan, R. K. Hartman, K. W.

Westberg, and R. E. Systma Reed. 2010. Scales for Rating the Behavioral Characteristics 
of Superior Students [Published Instrument]. Mansfield Center, CT: Creative Learning Press.

Ryser, G. R. and K. McConnell. 2004. SIGS Scales for Identifying Gifted Students. Waco, TX: Prufrock.

Schoenfeld, A. H. 1992. "Learning to Think Mathematically: Problem Solving, Metacognition and Sense-Making in Mathematics." In Handbook of Research on Mathematics Teaching and Learning, edited by D. A. Grouws, 165-197. New York: Macmillan.

Sheffield, Linda Jensen. 1999. "Serving the Needs of the Mathematically Promising." In

Developing Mathematically Promising Students, edited by L. J. Sheffield, 43-55. Reston:

National Council of Teachers of Mathematics.

Sheffield, Linda Jensen. 2003. Extending the Challenge in Mathematics : Developing

Mathematical Promise in K-8 Students. Thousand Oaks, CA: Texas Association for the Gifted and Talented; Corwin Press.

Smithers, A., P. Robinson, Centre for Education and Employment Research, and University of Buckingham. 2012. Educating the Highly Able. London, UK: The Sutton Trust. Speirs Neumeister, Kristie. 2007. "Perfectionism in Gifted Students: An Overview of Current Research." Gifted Education International 23 (3): 254-263.

Sriraman, Bharath. 2003. "Mathematical Giftedness, Problem Solving, and the Ability to Formulate Generalizations: The Problem-Solving Experiences of Four Gifted Students." Journal of Advance Academics 14 (3): 151-165.

Stanley, J. C. 2000. "Helping Students Learn Only what they Don'T Already Know." Psychology, Public Policy, and Law 6 (1): 216-222.

Sternberg, Robert J. 2003. "WICS as a Model of Giftedness." High Ability Studies 14 (2): 109-137.

Sternberg, Robert J. 2010. "WICS: A New Model for School Psychology." School Psychology International 31 (6): 599-616.

Sternberg, Robert J. and Elena L. Grigorenko. 2002. The Theory of Successful Intelligence as a Basis for Gifted Education.

Sternberg, Robert J., Linda Jarvin, and Elena L. Grigorenko. 2011. Explorations in Giftedness. Cambridge; New York: Cambridge University Press.

VanTassel-Baska, Joyce, Annie Xuemei Feng, and Brandy L. Evans. 2007. "Patterns of Identification and Performance among Gifted Students Identified through Performance Tasks: A Three-Year Analysis." Gifted Child Quarterly 51 (3): 218-231. 
Westberg, K. L., F. X. Archambault, S. M. Dobyns, and T. J. Salvin. 1993. An Observational Study of Instructional and Curricular Practices used with Gifted and Talented Students in Regular Classrooms. Storrs, CT: National Research Center on the Gifted and Talented; University of Connecticut.

Westberg, K. L. and M. E. Daoust. 2004. The Results of the Replication of the Classroom Practices Survey Replication in Two States. Storrs, CT: National Research Center on the Gifted and Talented; University of Connecticut.

Williams, Peter, Sir. 2008. Independent Review of Mathematics Teaching in Early Years Settings and Primary Schools. Nottingham: Department for Children, Schools and Families. 